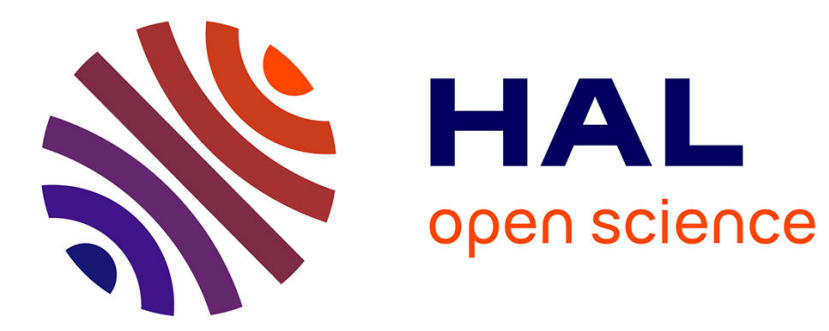

\title{
Dielectric impedance spectroscopy of polymer-coated microelectrodes for adsorption monitoring of proteins within polymer microchannels
}

\author{
Mohammed Kechadi, Lila Chaal, Bernard Tribollet, Jean Gamby
}

\section{- To cite this version:}

Mohammed Kechadi, Lila Chaal, Bernard Tribollet, Jean Gamby. Dielectric impedance spectroscopy of polymer-coated microelectrodes for adsorption monitoring of proteins within polymer microchannels. Journal of electroanalytical chemistry and interfacial electrochemistry, 2015, 737, pp.108-113. 10.1016/j.jelechem.2014.09.028 . hal-01111522

\author{
HAL Id: hal-01111522 \\ https://hal.science/hal-01111522
}

Submitted on 17 Sep 2015

HAL is a multi-disciplinary open access archive for the deposit and dissemination of scientific research documents, whether they are published or not. The documents may come from teaching and research institutions in France or abroad, or from public or private research centers.
L'archive ouverte pluridisciplinaire HAL, est destinée au dépôt et à la diffusion de documents scientifiques de niveau recherche, publiés ou non, émanant des établissements d'enseignement et de recherche français ou étrangers, des laboratoires publics ou privés. 
Dielectric Impedance spectroscopy of polymer-coated microelectrodes for adsorption monitoring of proteins within polymer microchannels

\author{
Mohammed Kechadi, ${ }^{\text {b,c }}$ Lila Chaal, ${ }^{c}$ Bernard Tribollet ${ }^{\text {a,b }}$ and Jean Gamby ${ }^{a, b, *}$ \\ ${ }^{a}$ CNRS, UMR 8235, LISE, F-75005, Paris, France \\ ${ }^{b}$ Sorbonne Universités, UPMC Univ Paris 06, UMR 8235, Laboratoire Interfaces et Systèmes \\ Electrochimiques, F-75005, Paris, France \\ ${ }^{c}$ Laboratoire d'Electrochimie, Corrosion et de Valorisation Energétique (LECVE) \\ Faculté de Technologie, Université A. MIRA - Béjaia (06000), Algérie
}

“ Corresponding author: jean.gamby@upmc.fr Tel: +33 1442736 40; Fax: +33 14427 4074; 


\begin{abstract}
The present work illustrates results obtained using dielectric impedance spectroscopy for adsorption monitoring of macromolecules like bovine serum albumin (BSA) onto insulated polymer in microchip. BSA does not need to be labelled but it must be attached to the polymer surface coupled with the microelectrodes. Modelling the microchip interface using an appropriate equivalent circuit allowed us to extract the value of the interfacial impedance for ultralow protein concentrations. The promising results were obtained with this methodology making it competitive in comparison with other transductions for bioanalytical developments.
\end{abstract}

Keywords: Dielectric; insulated polymer; microchip; impedance; adsorption 


\section{INTRODUCTION}

In the last decade, the increased use of miniaturized devices for biosensing is mainly due to the dual advantage of microsystems: adsorption test requires a smaller amount of bio sample immobilized in a fluidic microchannel than in traditional systems, and it allows the implementation of fast and cheap analytical methods. To enhance sensitivity detection on polymer microchannel, various strategies have been used to modify the polymer substrate surface properties via micro or nanostructuration. The two classical approaches are bottom-up or top-down to nanotechnology [1],[2],[3]. Indeed development of chemically modified polymer materials results in modified physical properties following electromechanical [4], [5], optical [6], [7] or electrical [8] external excitation. Thus the control of the surface properties of the polymer is the key parameter for development of many applications in MEMS or microfluidic domains.

Laser excimer photoablation is one of the top-down microfabrication approaches leading to microsized or nanosized structures on polymer surface. Polyethylene Terephthalate (PET) [9],[10],[11], Polyimide (PI) [12], and Polycarbonate (PC) [6] are the most used substrates into which laser photoablation generates well-defined microcavities depending to the mask geometry located between the excimer laser photon and the polymer sheet. It was observed that laser induces an increased roughness of the polymer surface and generates new functional groups on its surface [12]. This may open a new way to a bottom-up approach of setting specific and ordered biomolecules to create new functional centers on a polymer substrate [11].

Among the various new or adapted transductions developed for microchip, dielectric impedance spectroscopy through thin polymer layer comprised between two microelectrodes is a powerful technique for detection due to the absence of direct contact between the microelectrodes and the flow microchannel [13],[14]. The thin polymer layer comprises 
between the two planar microelectrodes and the microchannel can be viewed as dielectric component for which the physical properties can be measured as the response to an external electrical excitation. In previous papers, it has been demonstrated how to distinguish the impedance contribution of the surrounding polymer to the flow microchannel impedance response [15], [16]. In this paper, we demonstrate the possibility to probe the interfacial dielectric impedance change for monitoring protein adsorption through electrostatic interactions with the ionisable groups on the photoablated polymer in microchip. This is illustrated with a procedure to analyze the dielectric impedance spectroscopy of the device when the bovine serum albumine (BSA) interacts by adsorption onto the PET photoablated surface. Indeed, the interfacial impedance changes during the BSA adsorption can be monitored with accuracy and sensitivity.

\section{Materials and methods}

\subsection{Chemicals}

$1 \times 10^{-2} \mathrm{M} \mathrm{NaCl}$ was used as background electrolyte (BGE) solution where the checked $\mathrm{pH}$ was at 9 using $\mathrm{NaOH}$ and $\mathrm{HCl}$ solutions. $1 \times 10^{-3} \mathrm{M} \mathrm{NaOH}$ (from Sigma-Aldrich) was used as washing solution in a regenerating step. Bovine serum albumine (BSA, 96\%) was purchased from VWR International. BSA has a molecular mass of $66.43 \mathrm{kDa}$ and contains 610 amino acids with a value of 4.9 as isoelectric point $(\mathrm{pI})$. This protein was selected due to its capacity to adsorb on bare polymer surfaces. The diluted BSA samples were obtained after dilution in the BGE solution.

\section{2 Apparatus}

Measurements were performed in alternative mode at $100 \mathrm{mV}$ ac with a frequency range between $1 \mathrm{MHz}$ and $100 \mathrm{~Hz}$. The DC potential between the two microelectrodes was set to zero $\left(=0 \mathrm{~V}_{\mathrm{DC}}\right)$. The impedance response of the microdevice is recorded by Solartron FRA 
1255 B (Frequency Response Analyser) coupled to Dielectric Interface 1296 which extends the range of the frequencies between $10 \mu \mathrm{Hz}$ to $10 \mathrm{MHz}$. The current registered range is extended from $6 \mathrm{~mA}$ to $100 \mathrm{fA}$, which allows to measure a higher impedance $(100 \Omega$ à $100 \mathrm{~T}$ $\Omega)$. The experimental data are collected by SMaRT software.

\subsection{Microchannel Networks}

Measurements were carried out through a trapezoidal cross-section shaped (45 $\mu \mathrm{m}$ depth, 100 $\mu \mathrm{m}$ width and $1.4 \mathrm{~cm}$ length) Polyethylene Terephthalate (PET) photoablated microchannel. The detection was achieved using hydride carbon ink/gold nanoparticules electrodes, thermally laminated by a $35 \mu \mathrm{m}$ thick layer polyethylene/ polyethylene terephthalate (PE/PET) at $135^{\circ} \mathrm{C}$ and a 2 bar pressure. The role of the gold nanoparticles was to increase the conductivity of the carbon microelectrodes which leads to no resistance at the PET / microelectrode interface. The separation distance between both microelectrodes was $120 \mu \mathrm{m}$ edge to edge. The separation distance in the PET band between the two planar microelectrodes and the main microchannel was equal to $5 \mu \mathrm{m}$ and the detection surface area per microelectrode was $88 \times 100 \mu \mathrm{m}^{2}$ (Fig.1A).

\section{- Figure 1-}

\subsection{Dielectric Impedance Spectroscopy}

As displayed in Fig. 1B the global experimental impedance, $Z_{G, \exp }(\omega)$, measured through the non contact microchip device contains two contributions. Indeed, it can be viewed as a parallel association between the current streamlines passing through the two microelectrodes separated by the $120 \mu \mathrm{m}$-PET dielectric layer and by the $5 \mu \mathrm{m}$-PET dielectric layer with isolated electrodes from the microchannel [14],[15]. When the microchannel is empty the measured impedance corresponds only to $Z_{2, \exp }(\omega)$. As a consequence, the admittance $Z_{1}^{-1}(\omega)$ through the microchannel can be deduced by subtracting the experimental value of 
the admittance $Z_{2, \text { exp }}^{-1}(\omega)$ from the experimental value of the admittance $Z_{G \text {,exp }}^{-1}(\omega)$ recorded with a filled microchannel, as expressed in Equation. 1.

$$
Z_{G, \exp }^{-1}(\omega)=Z_{1}^{-1}(\omega)+Z_{2, \exp }^{-1}(\omega)
$$

where the experimental impedances $Z_{G, \exp }(\omega)$ and $Z_{2, \exp }(\omega)$ were obtained from the measurement of impedance in the filled and empty microchannel, respectively. The simulated impedance $Z_{1, \text { sim }}(\omega)$ written in Equation 2 was represented by the series association of the impedance of the $5 \mu \mathrm{m}$-PET layer, the impedance of the PET/microchannel interface and the impedance of the solution. The impedance of the $5 \mu \mathrm{m}$-PET was found to be close to a pure capacitive behavior. Indeed, it was represented by a constant phase element (CPE) model (Equation 3) where the CPE exponent, $\alpha_{1, P E T}$, was nearly 1 (vide infra). The impedance of the PET/microchannel interface was also analyzed with a CPE behavior (Equation 4). Physically the CPE element, $Q_{\text {int }}$, reflects capacitance and/or resistance distribution in the cavities of the microstructured PET surface. In brief, we consider the CPE element as to the square root of these parameters taking into consideration an analogy with the De Levie impedance defined as the square root of the smooth surface impedance. As expected, the CPE exponent, $\alpha_{i n t}$, was found equal to 0.5 . At this stage this result is sufficient to relate it with the impedance of a microstructured surface generated by laser photoablation process. [15],[16]. Assuming that both microelectrodes were identical, $Z_{1, P E T}$ and $Z_{\text {int }}$ contribute twice to the overall impedance. Then, the impedance for the solution microchannel was represented in equation 5 by taking into account the parallel association of the microchannel resistance, $R_{\mathrm{S}}$, and the cell capacitance, $C_{\mathrm{S}}$, which corresponds to the geometrical capacitance.

$$
Z_{1, \text { sim }}(\omega)=2 Z_{1, P E T}(\omega)+2 Z_{\text {int }}(\omega)+Z_{\text {microchannel }}(\omega)
$$

with:

$$
Z_{1, P E T}(\omega)=\frac{1}{(j \omega)^{\alpha_{1, P E T}} Q_{1, P E T}}
$$




$$
\begin{aligned}
& Z_{\text {int }}(\omega)=\frac{1}{(j \omega)^{\alpha_{\mathrm{int}}} Q_{\mathrm{int}}} \\
& Z_{\text {microchannel }}(\omega)=\frac{R_{S}}{1+j \omega C_{S} R_{S}}
\end{aligned}
$$

\section{Results and discussions}

\subsection{Procedure for adsorption monitoring on PET}

The experiments were performed in filled microchannel using BSA solution diluted in the BGE solution. The real-time monitoring of the impedance modulus change displayed in Figure 2 was recorded by applying $0.1 \mathrm{~V}$ ac voltage amplitude at fixed frequency $(200 \mathrm{~Hz})$. It corresponds to a typical curve for adsorption monitoring (sensorgram) obtained according to the experimental procedure described below. As expected, the Photoablation of the polymer induces surface charges on PET surface on which adsorption of biomolecules can occur in the electrical double layer. [10]

In our case at $\mathrm{pH}$ 9, functional groups such as Carboxylate or phenolate can serve for enhance electrostatic BSA adsorption on PET. As observed on sensorgram the process in such condition was reversible (BSA desorption). The solutions were loaded into the microchannel using a high precise micropump with a flow rate equal to $F_{v}=7.2 \mu \mathrm{L} \min ^{-1}$. Taking into account the microchannel dimensions, the Reynolds number can be estimated as:

$$
\operatorname{Re}=\frac{u h}{v}
$$

with $u=\frac{F_{V}}{S_{C}}$ is defined as the microchannel flow rate in $\mathrm{m} \mathrm{s}^{-1}$ through the trapezoidal cross area, $S_{C}\left(4.05 \times 10^{-9} \mathrm{~m}^{2}\right), v$ the kinematics viscosity of water $\left(10^{-6} \mathrm{~m}^{2} \cdot \mathrm{s}^{-1}\right)$, and $h$ is the microchannel height equals to $45 \mu \mathrm{m}$ (see Figure 1A).

The calculated value of $R e$ was found equal to 1.35 , which corresponds to a laminar flow regime. The microchannel was first loaded with the BGE solution over $360 \mathrm{~s}$ (step 1, Figure 2). The mean value of the impedance modulus $\left(8.8 \times 10^{7} \Omega\right)$ is used as reference status for PET 
microchannel without BSA. During the step two, protein adsorption stage was monitored for $600 \mathrm{~s}$ after the introduction of sample ( $\left.66.4 \mathrm{ng} \mathrm{L}^{-1} \mathrm{BSA}\right)$ diluted in the BGE solution. The protein desorption stage was monitored by injecting of the BGE solution (without protein) over a $1100 \mathrm{~s}$ period (step 3, Figure 2). The fourth step consisted in the PET surface regeneration by introducing $10^{-3} \mathrm{M} \mathrm{NaOH}$ over a 40 minutes period. This last step allowed the reference state to be recovered. A third introduction of the BGE solution (step 5, Figure 2) shows that the value of the impedance modulus corresponds to the former value measured during the first step. The use of sodium hydroxide solution for regenerating PET surface is commonly used in several procedures to effectively remove any trace of adsorbed protein on materials [17],[18]. Due to the BSA high hydrophobicity, the regeneration step is clearly helpful and permits to break interactions between BSA and the PET ionisable groups [18] on photoablated PET. This opens the way of a multi usable chip for several run experiments.

\section{- Figure 2 -}

\subsection{Procedure for extracting dielectric parameter in microchannel}

The BSA adsorption/ desorption process, the washing procedure and the regenerating steps have been controlled by analyzing the PET surface by dielectric impedance spectroscopy. Each of these steps is illustrated by an impedance diagram in Nyquist representation displayed in Figure 3 that was recorded at stop flow in $1 \mathrm{MHz}$ to $100 \mathrm{~Hz}$ frequency range. The experimental procedure was carried out from $66.4 \mathrm{ng} \mathrm{L}^{-1}$ to $66.4 \mu \mathrm{g} \mathrm{L}^{-1}$ BSA concentrations. It is important to stress that all the experimental impedance measurements $\mathrm{Z}_{\mathrm{G} \text {,exp }}$ data between $1 \mathrm{MHz}$ to $100 \mathrm{~Hz}$ were corrected from the dielectric impedance of the cell (measured when the microchannel is empty), and the data analysis were performed on the impedance $Z_{1}$.

\section{- Figure 3 -}

The parameters summarized in Table 1 were obtained after fitting procedure of the Nyquist diagrams using the electrical equivalent circuit (Figure 1B) for each stop point i.e. at $t=100 \mathrm{~s}$, 
$t=700 \mathrm{~s}, t=1500 \mathrm{~s}$ and $t=17400 \mathrm{~s}$. It can be observed from $1 \mathrm{MHz}$ to $1 \mathrm{kHz}$ that no significant change is observed on the Nyquist diagrams. Conversely, slight variations on the low-frequency capacitive branches were recorded from $1 \mathrm{kHz}$ to $100 \mathrm{~Hz}$ that were ascribed to BSA adsorption or desorption according to the step involved. On step 2, an increase for the CPE element, $Q_{\text {int }}$, was observed in the presence of $66.4 \mathrm{ng} \mathrm{L}^{-1}$. As shown in Table 1, the initial value of $Q_{\text {int }}$ during the first step was not recovered after the second introduction the BGE solution (step 3). This indicates that the PET microchannel contains few BSA molecules adsorbed on its surface and that the desorption stage has not been completely effective. However, it is important to highlight that the obtained Nyquist diagrams are superimposable for the steps 1 and 5 with the BGE solution. In other words, this indicates that the regeneration procedure using $10^{-3} \mathrm{M} \mathrm{NaOH}$ is effective and mandatory.

\section{- Table 1 -}

The Nyquist impedance measurements were performed during the step 2, at a quasi-steady state for various BSA concentrations loaded in PET microchannel, as shown in Figure 4A-E. For BSA free and BSA concentrations the corresponding diameter loop varies with the microchannel conductivity, which is mainly set by the $\mathrm{NaCl}$ concentration. In the low frequency domain, the capacitive branches are slightly inclined and are independent of BSA concentrations. These conclusions are supported by the Bode plot representation of the real and imaginary parts displayed in Figures 4F-J and Figure 4K-L, respectively. It is observed that the imaginary part slopes are quite similar. In the intermediate frequency range between $10^{3}$ and $10^{4} \mathrm{~Hz}$, the experimental data and the theoretical fit seems less superimposable. This area corresponds to the beginning effect of the resistive contribution and the end of the capacitive effect observed in the high frequencies. This transition between the two effects is represented by a combination of equations 3-5 which may explain that we do not get an excellent fit of the experimental data. The purpose of this present model is to fit the 
experience only with parameters having a physical meaning in the microdevice. Indeed, it is not necessary to add other components in the equivalent circuit for modeling the thin adsorbed organic layer. The changes on the values of $R_{\mathrm{S}}$ and $Q_{\text {int }}$ extracted from the theoretical model, as well as microscopy image are sufficient to prove that a thin layer of protein is adsorbed.

\section{- Figure 4 -}

In order to quantify the change on the dielectric parameters through the PET microchannel with ultralow BSA in the flow channel, the proposed circuit model in Figure 1b was used to fit $Z_{1}(\omega)$ Nyquist diagrams (Figures 4A-E ) and the corresponding Bode plots (Figures 4F-L). The parameters obtained are, as expected, in accordance with the model because the assumed independent variables such as $Q_{1}$, PET, $\alpha_{1, \mathrm{PET}}, C_{\mathrm{S}}$ and $\alpha_{\mathrm{int}}$ were found identical to those published previously [15]. For a best fitting procedure these latter are imputed as fixed parameters while the microchannel resistance, $R_{\mathrm{S}}$, and the interfacial capacitance, $Q_{\mathrm{int}}$, were considered as variables. When BSA concentration varies from 0 to $6.64 \mu \mathrm{g} \mathrm{L}^{-1}, R_{\mathrm{S}}$ decreases by $30 \%$ while $Q_{\text {int }}$ increases by $150 \%$.

- Table 2 -

As we obtained for ultralow BSA concentration in the microchannel, the obtained resistance change is negligible. We can assume a low $R_{\mathrm{S}}$ variation because the bulk effect is predominant. Conversely, when the BSA concentration increases, the surface effect becomes non negligible ( $Q_{\text {int }}$ increases). An equilibrium state is then reached between BSA in solution and BSA adsorbed on PET. This can explain why the value of $R_{\mathrm{S}}$ decreases while $Q_{\text {int }}$ increases concomitantly.

These results highlight the effect of protein adsorption on microchannel resistance. Indeed, the measured microchannel resistance combines the effects of the volume resistance and the 
resistance at the vicinity of PET surface due to the excess of surface charges induced by the adsorbed BSA and excess of the counterions concentration. As a consequence, it is obvious that the electrical conductivity should not be treated as constant independent along the microchannel height.

\section{Conclusion}

These results demonstrate the ability of dielectric impedance spectroscopy in a non-contact microdevice for detecting ultralow amounts of protein adsorbed on insulated polymer. Thus, impedance sensorgram of the module at fixed $200 \mathrm{~Hz}$ frequency were recorded for the BSA adsorption in the detection zone of the microfluidic chip. Variation of the impedance modulus is found to be sensitive to the concentration of the protein in the solution microchannel, and therefore of the adsorbed protein. The data analysis and fitting procedure using the proposed model is valid for frequency range comprised between $1 \mathrm{MHz}$ to $100 \mathrm{~Hz}$. The more sensitive parameters are the microchannel resistance, $R_{\mathrm{S}}$, and the interfacial CPE parameter, $Q_{\text {int }}$. This latter varies by $150 \%$ from BSA free to $6.64 \mu \mathrm{g} \mathrm{L} \mathrm{L}^{-1}$ BSA diluted in the BGE solution, much more than the microchannel resistance. This allowed us to foresee that electrical detection such as dielectric impedance in this kind microdevice for real time measurement acquisition at fixed frequency is a promising method for biosensing on insulated materials.

\section{Acknowledgments}

This research was supported by the UPMC and the French Institute of Research and development (IRD). The authors thank the Prof. Hubert Girault for access to experimental facilities in the center of micro and nanotechnology at EPFL, Lausanne. 


\section{References}

[1] L. Persano, A. Camposeo, D. Pisignano, Integrated bottom-up and top-down soft lithographies and microfabrication approaches to multifunctional polymers, Journal of Materials Chemistry C, 1 (2013) 7663-7680.

[2] X. Wang, X. Wang, R. Fernandez, L. Ocola, M. Yan, A. La Rosa, Electric-Field-Assisted Dip-Pen Nanolithography on Poly(4-vinylpyridine) (P4VP) Thin Films, ACS Applied Materials \& Interfaces, 2 (2010) 2904-2909.

[3] M.A. Bartlett, M. Yan, Photochemical immobilization of polymer thin films on solid substrates, Polym. Mater. Sci. Eng., 83 (2000) 451-452.

[4] C. Bucci, R. Fieschi, G. Guidi, Ionic Thermocurrents in Dielectrics, Physical Review, 148 (1966) 816-823.

[5] J. Gamby, M. Lazerges, C. Pernelle, H. Perrot, H.H. Girault, B. Tribollet, Electroacoustic miniaturized DNA-biosensor, Lab on a Chip, 7 (2007) 1607-1609.

[6] J. Gamby, A. Rudolf, M. Abid, H.H. Girault, C. Deslouis, B. Tribollet, Polycarbonate microchannel network with carpet of Gold NanoWires as SERS-active device, Lab on a Chip, 9 (2009) 1806-1808.

[7] K. Wang, Y.-S. Li, Silver doping of polycarbonate films for surface-enhanced Raman scattering, Vibrational Spectroscopy, 14 (1997) 183-188.

[8] J. Gamby, J.P. Abid, B. Tribollet, H.H. Girault, Nanomosaic network for the detection of proteins without direct electrical contact, Small, 4 (2008) 802-809.

[9] J.S. Rossier, P. Bercier, A. Schwarz, S. Loridant, H.H. Girault, Topography, Crystallinity and Wettability of Photoablated PET Surfaces, Langmuir, 15 (1999) 5173-5178.

[10] F. Bianchi, Y. Chevolot, H.J. Mathieu, H.H. Girault, Photomodification of Polymer Microchannels Induced by Static and Dynamic Excimer Ablation: Effect on the Electroosmotic Flow, Analytical Chemistry, 73 (2001) 3845-3853. 
[11] J. Gamby, M. Lazerges, H.H. Girault, C. Deslouis, C. Gabrielli, H. Perrot, B. Tribollet, Electroacoustic Polymer Microchip as an Alternative to Quartz Crystal Microbalance for Biosensor Development, Analytical Chemistry, 80 (2008) 8900-8907.

[12] M.A. Roberts, J.S. Rossier, P. Bercier, H. Girault, UV Laser Machined Polymer Substrates for the Development of Microdiagnostic Systems, Analytical Chemistry, 69 (1997) 2035-2042.

[13] J. Gamby, J.P. Abid, M. Abid, J.P. Ansermet, H.H. Girault, Nanowires Network for Biomolecular Detection Using Contactless Impedance Tomoscopy Technique, Analytical Chemistry, 78 (2006) 5289-5295.

[14] M. Faure, M. Kechadi, B. Sotta, J. Gamby, B. Tribollet, Contact Free Impedance Methodology for Investigating Enzymatic Reactions into Dielectric Polymer Microchip, Electroanalysis, 25 (2013) 1151-1158.

[15] M. Kechadi, J. Gamby, L. Chaal, H. Girault, B. Saidani, B. Tribollet, Polymer microchip impedance spectroscopy through two parallel planar embedded microelectrodes: Understanding the impedance contribution of the surrounding polymer on the measurement accuracy, Electrochimica Acta, 105 (2013) 7-14.

[16] M. Kechadi, J. Gamby, L. Chaal, B. Saidani, B. Tribollet, Free Contact Microchannel Impedance Through Two Antiparallel Planar Microelectrodes, Journal of Flow Chemistry, 3 (2013) 81-86.

[17] H. Urano, S. Fukuzaki, Kinetic Study of Desorption of Two Species of Bovine Serum Albumin from Alumina during Alkali Elution Process, Journal of Colloid and Interface Science, 252 (2002) 284-289.

[18] E.G. G. Spada, P. Giunchedi, Protein Delivery from Polymeric Nanoparticles World Academy of Science, Engineering and Technology, 52 (2011) 245249. 


\section{Table captions}

Table 1: Model parameters of impedance $Z_{1, \operatorname{sim}}(\omega)$ at different steps of procedure in Figure 1 . The values of the resulting $\chi^{2}$ statistic were obtained with errors of fitted values, $\sigma=0.01$, for frequency ranging from $1 \mathrm{MHz}$ to $100 \mathrm{~Hz}$.

Table 2: Model parameters of impedance $Z_{1, \operatorname{sim}}(\omega)$ at various BSA concentrations in the microchannel. The values of the resulting $\chi^{2}$ statistic were obtained with errors of fitted values, $\sigma=0.01$, for frequency ranging from $1 \mathrm{MHz}$ to $100 \mathrm{~Hz}$. 


\section{Figure Captions}

Fig. 1: Schematic view of the dielectric microelectrodes/ PET /microchannel (not to scale). A. Trapezoidal PET microchannel with the two planar embedded microelectrodes without contact. B. Cross section of the dielectric interface microelectrode/ PET/ microchannel and the corresponding dielectric impedances: $Q_{\mathrm{PET}, 1}$ for the $5 \mu \mathrm{m}$-PET layer impedance (thickness of PET without contact layer), $Q_{\mathrm{PET}, 2}$ for the $120 \mu \mathrm{m}$-PET layer impedance (distance separation between the two microelectrodes), $Q_{\text {int }}$ for the photoablated surface microchannel impedance, and $R_{\mathrm{S}}$ and $C_{\mathrm{S}}$ for the microchannel resistance and cell capacitance, respectively.

Fig. 2: Experimental impedance $Z_{\mathrm{G} \text { exp }}(\omega)$ measured with time at $200 \mathrm{~Hz}$ fixed frequency with a $0.1 \mathrm{~V}$ voltage amplitude at flow equals to $7.2 \mu \mathrm{L} \cdot \mathrm{min}^{1}$. Step $1: 10^{-2} \mathrm{M} \mathrm{NaCl}$ (BGE solution) over $360 \mathrm{~s}$. Step 2: Introduction of $66.4 \mathrm{ng} \mathrm{L}^{-1} \mathrm{BSA}$ sample diluted in the BGE solution over 600 s. Step 3: The second introduction of the BGE solution over 1100 s. Step 4: introduction of the regenerating agent $\left(10^{-3} \mathrm{M} \mathrm{NaOH}\right)$ for $15200 \mathrm{~s}$. Step 5: The third introduction of the BGE solution over $200 \mathrm{~s}$. The red arrows indicate the time beginning of each change of solution. The green circles indicate the stop flow time for each impedance diagram acquisition (see Fig. 3).

Fig.3: The experimental Nyquist plots of the impedance $Z_{1, \exp }(\omega)$ measured at various stop flow indicated in Figure 2. Measurements performed between $1 \mathrm{MHz}$ and $100 \mathrm{~Hz}$ with a 0.1 $\mathrm{V}$ ac amplitude. A. Comparison between Step 1: BGE solution at $\mathrm{t}=100 \mathrm{~s}$ and Step 2: sample of $66.4 \mathrm{ng} \mathrm{L}^{-1} \mathrm{BSA}$ diluted in BGE solution at $\mathrm{t}=700 \mathrm{~s}$. B. Comparison between Step 1 and Step 3: the second introduction of BGE solution at $\mathrm{t}=1500$ s. C. Comparison between Step 1 and Step 5: the third introduction of BGE at $\mathrm{t}=17400 \mathrm{~s}$.

Fig. 4: Experimental $Z_{1, \text { exp }}(\omega)$ and modeled $Z_{1, \text { sim }}(\omega)$ impedance from $1 \mathrm{MHz}$ to $100 \mathrm{~Hz}$ with a voltage of $0.1 \mathrm{Vac}$, in the presence of $10^{-2} \mathrm{M} \mathrm{NaCl}, \mathrm{BSA}$ at $6.64 \times 10^{1}, 3.32 \times 10^{2}, 6.64 \times 10^{2}$, $6.64 \times 10^{3} \mathrm{ng} \mathrm{L}^{-1}$ in BGE solution. A-E. Nyquist plots for BSA free then for an increase of BSA concentration. F-J. Real part vs frequency. K-L. Imaginary part $v s$ frequency. 
Tables

Table 1

\begin{tabular}{|c|c|c|c|c|c|c|c|}
\hline Step & $\begin{array}{c}Q_{1, \mathrm{PET}} \\
\times 10^{-11}\left(\mathbf{\Omega}^{-1} . \mathbf{s}^{\boldsymbol{\alpha}}\right)\end{array}$ & $\alpha_{1, \text { PET }}$ & $\begin{array}{c}\boldsymbol{R}_{\mathbf{S}} \\
\times 10^{7}(\mathbf{\Omega})\end{array}$ & $\begin{array}{c}\boldsymbol{C}_{\mathbf{S}} \\
\times 10^{-13}(\mathbf{F})\end{array}$ & $\begin{array}{c}\boldsymbol{Q}_{\text {int }} \\
\times 10^{-10}\left(\mathbf{\Omega}^{-\mathbf{1}} . \mathbf{s}^{\boldsymbol{\alpha}}\right)\end{array}$ & $\boldsymbol{\alpha}_{\text {int }}$ & $\begin{array}{l}\chi^{2} \\
(\%)\end{array}$ \\
\hline 1 & \multirow{4}{*}{2.3} & \multirow{4}{*}{0.98} & 4.1 & \multirow{4}{*}{2} & 7.5 & \multirow{4}{*}{0.5} & 4 \\
\hline 2 & & & 3.8 & & 7.9 & & 5 \\
\hline 3 & & & 3.8 & & 7.7 & & 6 \\
\hline 5 & & & 3.9 & & 7.6 & & 6 \\
\hline
\end{tabular}


Table 2

\begin{tabular}{|c|c|c|c|c|c|c|c|}
\hline $\begin{array}{c}\text { [BSA }] \\
\times 10^{-9}\left(\mathrm{~g} \mathrm{~L}^{-1}\right)\end{array}$ & $\begin{array}{c}Q_{1, \mathrm{PET}} \\
\times 10^{-11}\left(\mathbf{\Omega}^{-1} . \mathbf{s}^{\boldsymbol{\alpha}}\right)\end{array}$ & $\alpha_{1, \mathrm{PET}}$ & $\begin{array}{c}\boldsymbol{R}_{\mathbf{S}} \\
\times 10^{7}(\mathbf{\Omega})\end{array}$ & $\begin{array}{c}C_{\mathbf{S}} \\
\times 10^{-13}(\mathbf{F})\end{array}$ & $\begin{array}{c}Q_{\text {int }} \\
\times 10^{-10}\left(\boldsymbol{\Omega}^{-1} . \mathbf{s}^{\boldsymbol{\alpha}}\right)\end{array}$ & $\alpha_{\text {int }}$ & $\begin{array}{l}\chi^{2 .} \\
(\%)\end{array}$ \\
\hline 0 & \multirow{5}{*}{2.3} & \multirow{5}{*}{0.98} & 4.1 & \multirow{5}{*}{2} & 7.5 & \multirow{5}{*}{0.5} & 4 \\
\hline 66.4 & & & 3.8 & & 7.9 & & 5 \\
\hline 332 & & & 3.5 & & 9.3 & & 6 \\
\hline 664 & & & 3.3 & & 16 & & 5 \\
\hline 6640 & & & 2.9 & & 19 & & 7 \\
\hline
\end{tabular}


Figure 1

A

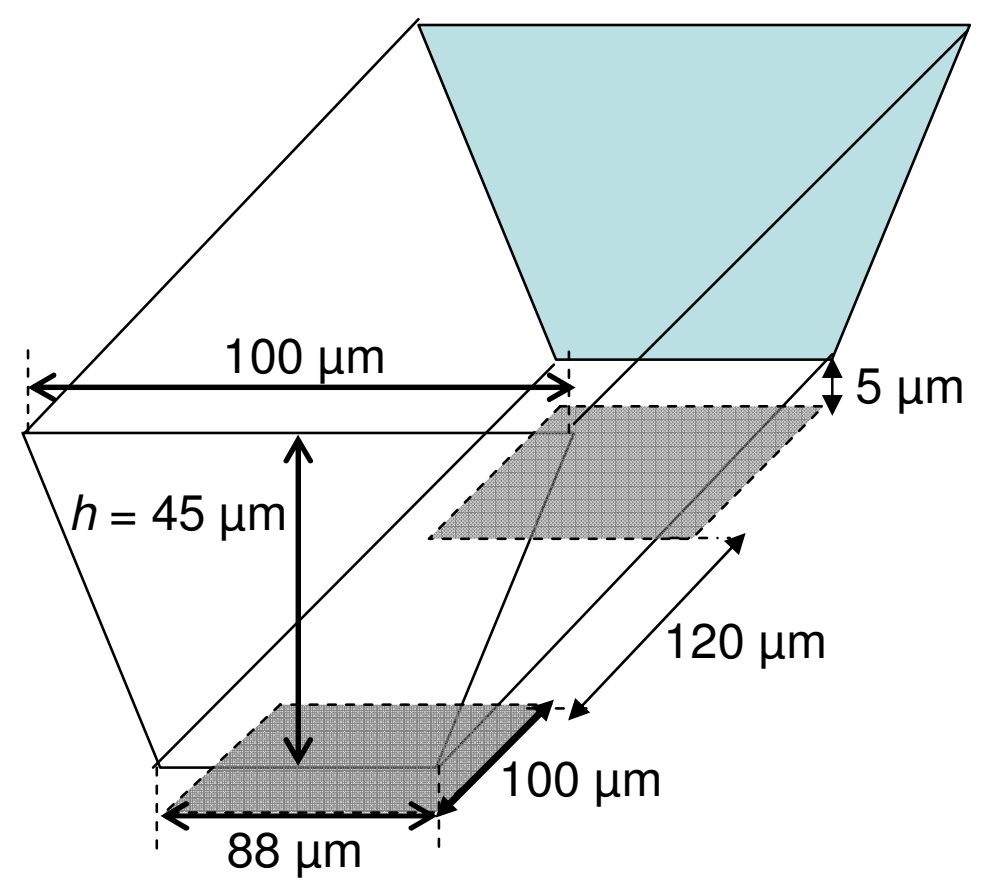


Figure 1

B

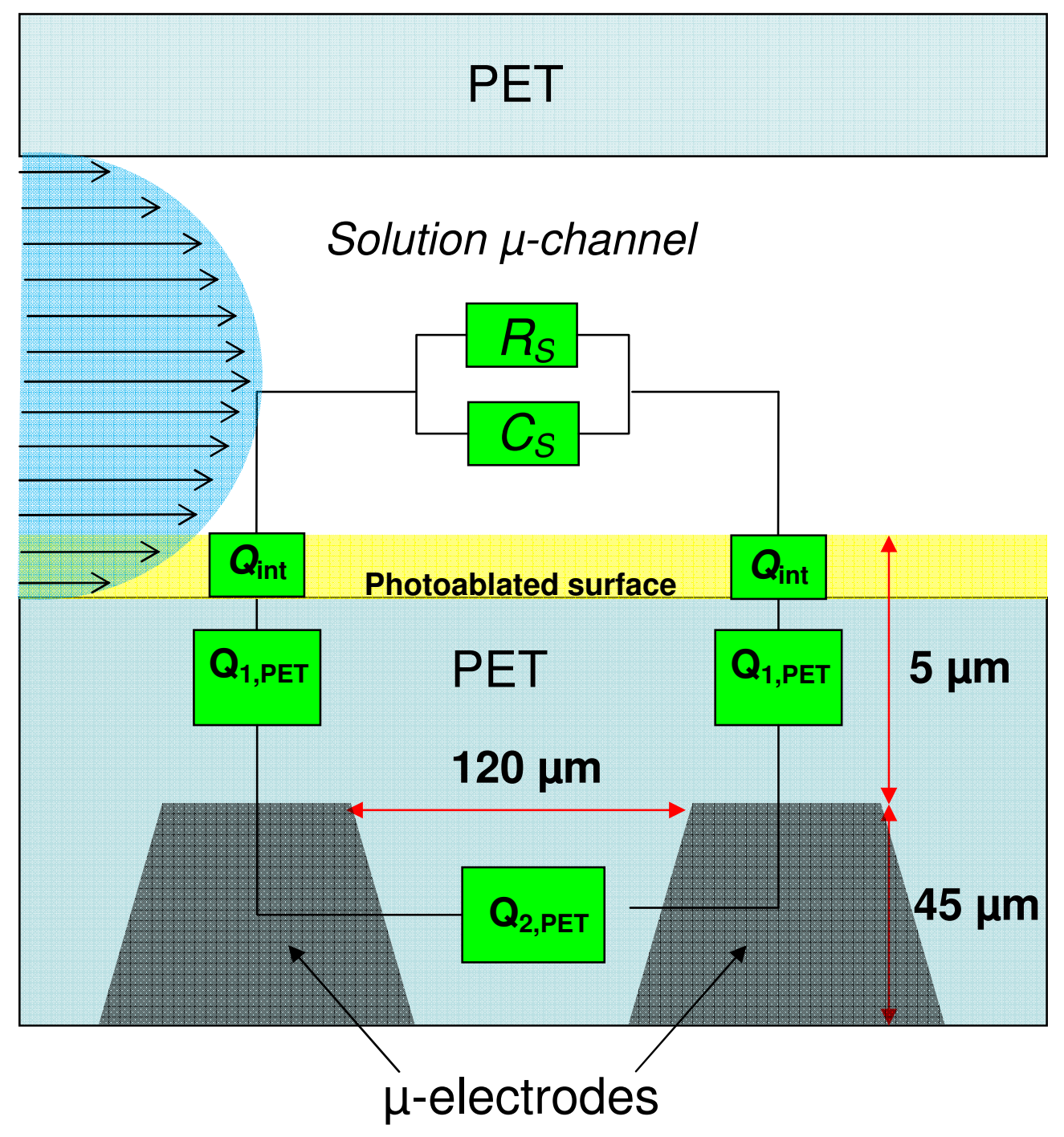


Figure 2

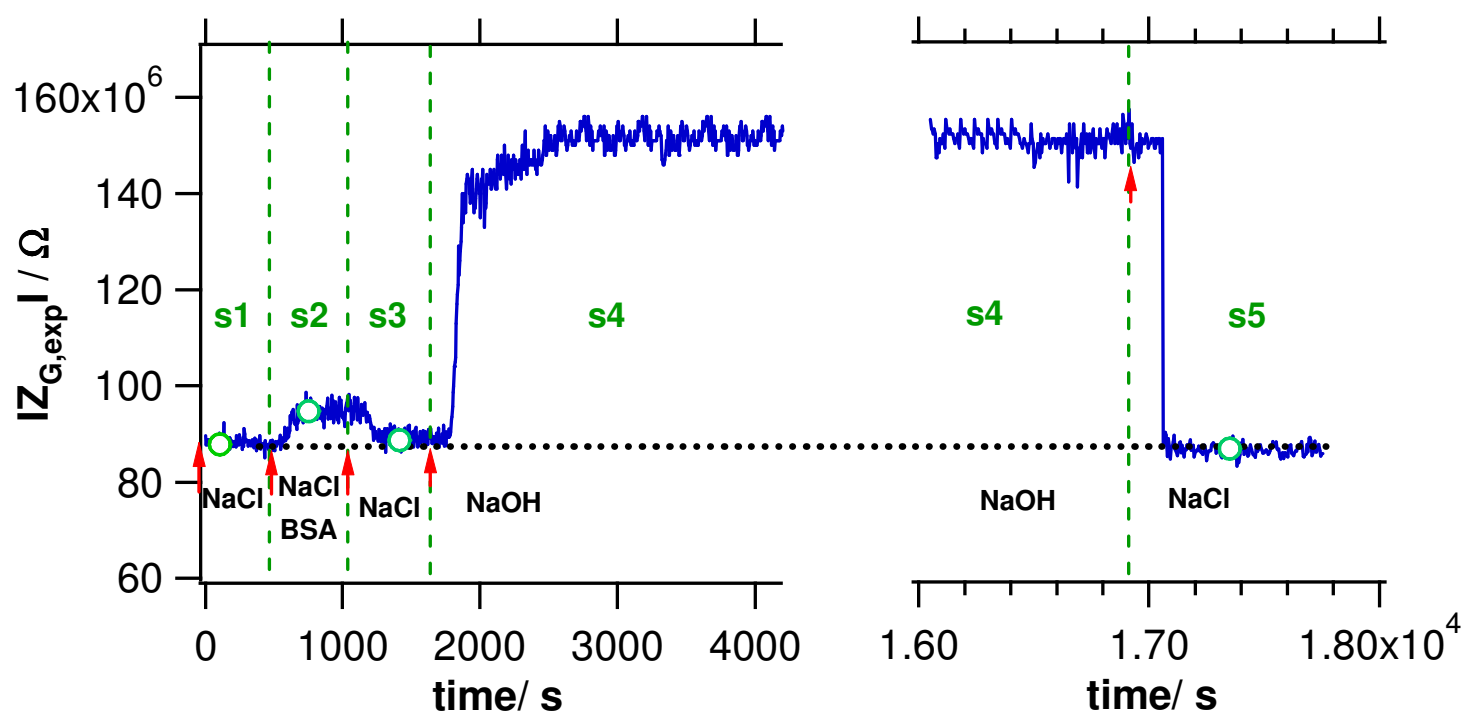


Figure 3
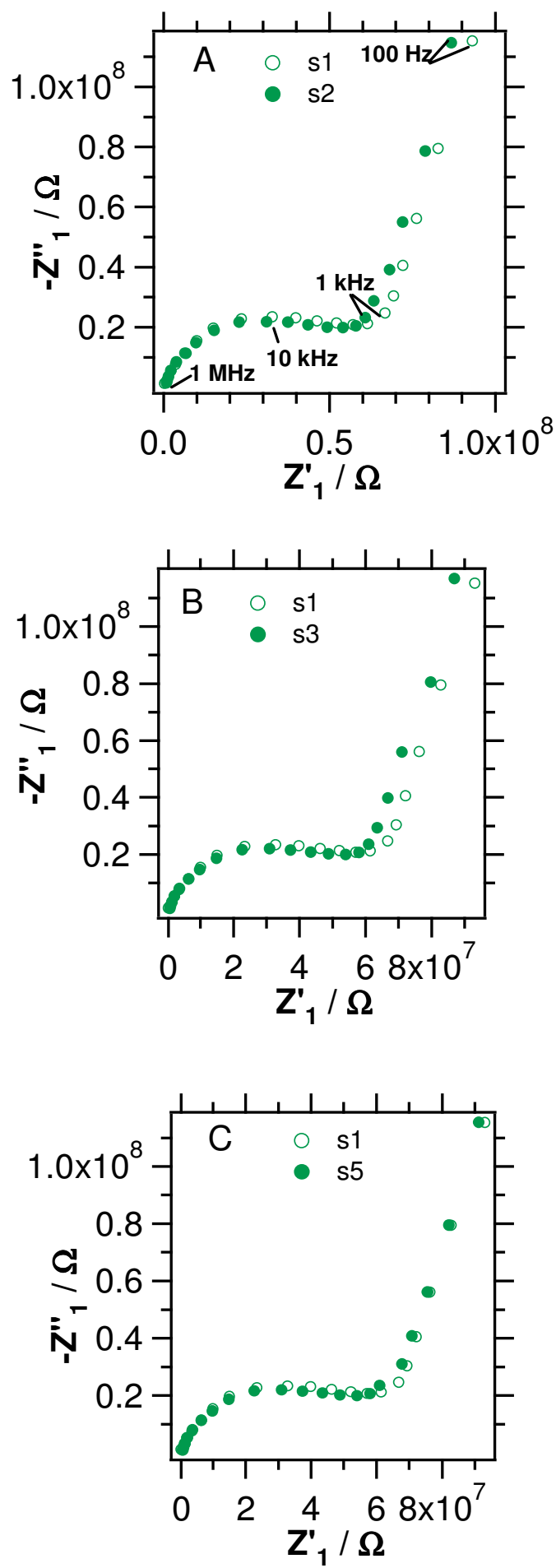
Figure 4
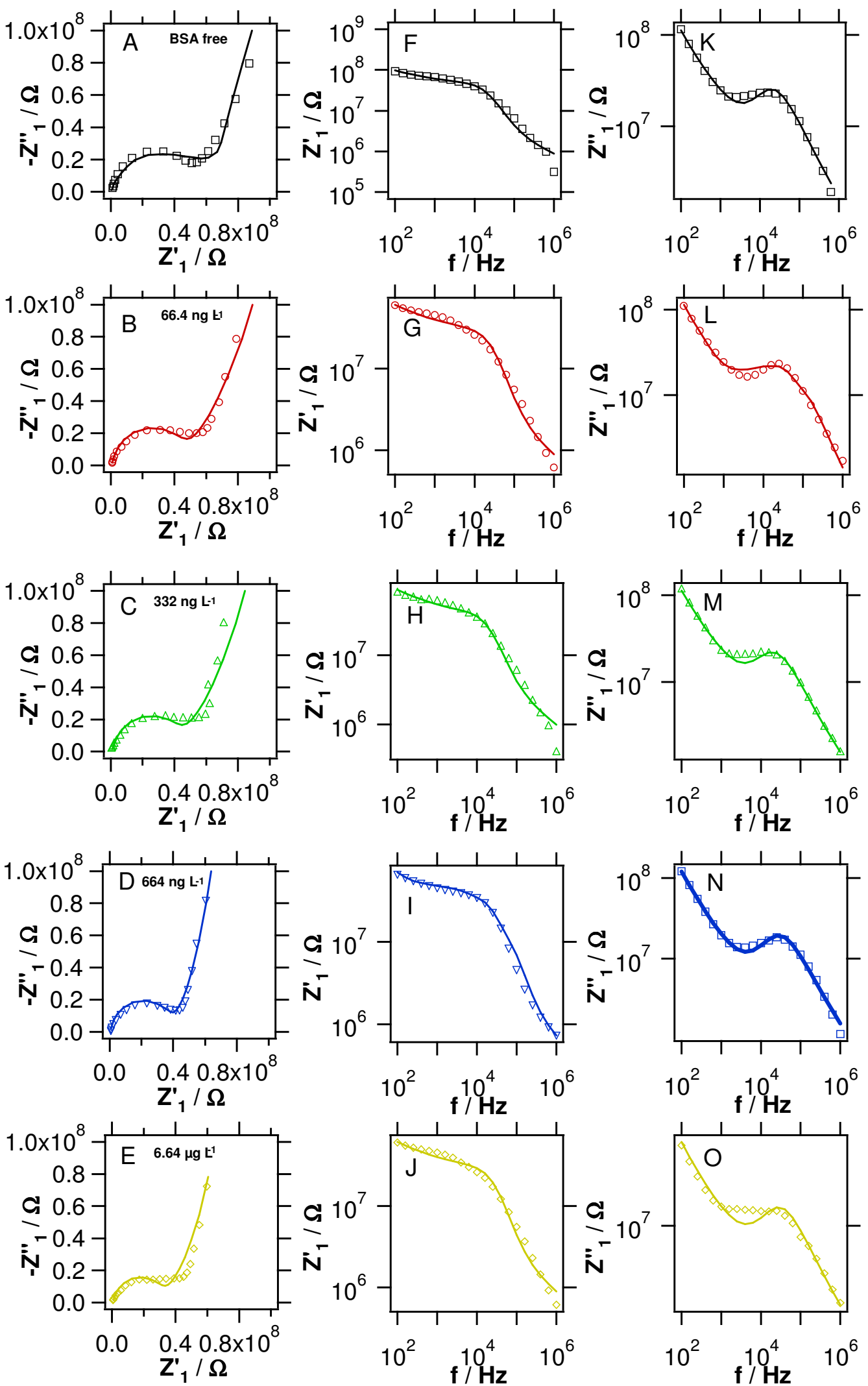